Article

\title{
Poly (Lactic Acid)/Thermoplastic Starch Films: Effect of Cardoon Seed Epoxidized Oil on Their Chemicophysical, Mechanical, and Barrier Properties
}

\author{
Rosa Turco $\left.{ }^{1}{ }^{(}\right)$, Rodrigo Ortega-Toro ${ }^{2}$, Riccardo Tesser ${ }^{1}$, Salvatore Mallardo ${ }^{3}{ }^{(D)}$, \\ Sofia Collazo-Bigliardi ${ }^{2,4}$, Amparo Chiralt Boix ${ }^{4}$, Mario Malinconico ${ }^{3}$, Massimo Rippa ${ }^{5}$, \\ Martino Di Serio ${ }^{1,6}$ (D) and Gabriella Santagata ${ }^{3, *}$ \\ 1 Department of Chemical Sciences, University of Naples Federico II, \\ Complesso Universitario di Monte Sant'Angelo, 80126 Naples, Italy \\ 2 Programa de Ingeniería de Alimentos, Facultad de Ingeniería, Universidad de Cartagena, \\ Food Pakaging and Shelf Life Research Group, Carrera 6 \# 36-100, Cartagena de Indias D.T y C 130001, Colombia \\ 3 Institute for Polymers, Composites and Biomaterials, National Council of Research, Via Campi Flegrei 34, \\ 80078 Pozzuoli, Italy \\ 4 Instituto de Ingeniería de Alimentos para el Desarrollo, Universidad Politécnica de Valencia, \\ Camino de Vera s/n, 46022 Valencia, Spain \\ 5 Institute of Applied Sciences and Intelligent Systems, National Council of Research, Via Campi Flegrei 34, \\ 80078 Pozzuoli, Italy \\ 6 International Research Organization for Advanced Science and Technology (IROAST), \\ University of Kumamoto, Kumamoto 860-8555, Japan \\ * Correspondence: santagata@ipcb.cnr.it; Tel.: +39-08-1867-5372
}

Received: 1 August 2019; Accepted: 2 September 2019; Published: 8 September 2019

check for updates

\begin{abstract}
In this work, biodegradable films based on poly (lactic acid) (PLA) and corn thermoplastic starch (TPS), additivated with epoxidized cardoon oil plasticizer (ECO) at 3\% by weight with respect to PLA mass fraction, were prepared by melt extrusion process and compression molding. The effect of ECO on structural, thermal, mechanical, barrier, and spectral optical properties of the films was investigated. Spectroscopic analysis evidenced the development of physical interaction between oil and polymers, mainly PLA. In addition, no oil migration occurrence was detected after six months of film preparation, as evidenced by oil mass evaluation by precipitation as well as by ${ }^{1} \mathrm{H}-\mathrm{NMR}$ methods, thus highlighting the good inclusion of oil inside the polymeric network. The plasticizing action of the oil induced a lean improvement of the interfacial adhesion between hydrophobic PLA and hydrophilic TPS, particularly accentuated in PLA80_ECO composition, as evidenced by morphological analysis of blend fracture surfaces. TGA data underlined that, differently from TPS-based films, PLA-based systems followed one degradative thermal profile suggesting a slight compatibilization effect of epoxidized oil in these films. The shifting of Tg values, by differential scanning calorimetry (DSC) analysis, indicated a weak miscibility at molecular level. Generally, in the investigated blends, the phase separation between PLA and TPS polymers was responsible for the mechanical properties failing; in particular, the tensile strength evidenced a negative deviation from the rule of mixtures, particularly marked in TPS-based blends, where no physical entanglements occurred between the polymers since their immiscibility even in presence of ECO. The epoxidized oil strongly improved the barrier properties (water vapor permeability (WVP) and oxygen permeability $\left(\mathrm{O}_{2} \mathrm{P}\right)$ ) of all the films, likely developing a physical barrier to water and oxygen diffusion and solubilization. With respect to neat PLA, PL80 and PL80_ECO films evidenced the improvement of surface wettability, due to the presence of polar groups both in TPS (hydroxyl residues) and in epoxidized oil (oxirane rings). Finally, following to the conditioning in climatic chamber at $\mathrm{T}=25{ }^{\circ} \mathrm{C}$ and $\mathrm{RH}=50 \%$, PLA80 film became opaque due to TPS water absorption, causing a light transmittance decreasing, as evidenced by spectral optical analysis.
\end{abstract}


Keywords: biomass recovery; cardoon epoxidized oil; poly (lactic acid); thermoplastic starch; bioplastics

\section{Introduction}

At present, in Europe, packaging applications represent about $40 \%$ of the total plastics demand [1]. Petroleum-based plastics have been accumulated as postconsumer wastes difficult to dispose due to their large volume and inability to biodegrade or to compost. As a consequence, they gather in ground and water sources, thus resulting in the huge waste streaming concern and in environmental pollution [2]. A valid alternative to reduce the consumption of conventional plastics is the use of biodegradable ones $[3,4]$.

Academia, industry, and government have been studying alternatives to mitigate the impact of petroleum-based plastics through research, development, innovation, and commercialization of biodegradable polymer-based products, coming from renewable sources [5].

At present, the most common biodegradable polymers are polylactide (PLA), poly (hydroxybutyrate) (PHB), poly (glycolic acid) (PGA), and natural-based polymers like starch, cellulose, proteins, and gums, inter alia [6,7]. The peculiar property of biodegradable plastics is their ability to degrade in composting conditions [8]. Among them, one of the biopolymers with the highest production and potential commercialization is PLA, a linear aliphatic thermoplastic polyester derived from lactic acid. Commercial PLAs are copolymers of poly (L-lactic acid) (PLLA) and poly (D,L-lactic acid) (PDLA), whose L- and D,L- enantiomer ratios are responsible for the peculiar PLA properties, such as melting temperature and crystallinity [9]. PLA is the most promising biodegradable polyester whose properties are comparable with the ones of high-performing petroleum-derived plastics. Indeed, its mechanical properties, such as tensile strength and Young's modulus, are comparable to those of poly (ethylene terephthalate) [10]. In addition, the biodegradation of PLA occurs by hydrolysis, followed by biodegradation via bacteria [11]. These worthy properties, together with its easy processability, occurring by means of the conventional industrial processing equipment, such as thermoforming, injection molding, film extrusion, blow molding, fiber spinning, and film forming, make PLA a leading candidate for substituting traditional oil-derived plastics in a wide range of industrial products, such as packaging materials [12]. Indeed, this polymer has a high barrier against water vapor and high tensile strength [11]. Unfortunately, the high cost, together with some drawbacks, such as brittleness, low flexibility, and low degradation rate, severely hamper PLA use in the engineering sectors [13]. Considerable efforts have been made to improve PLA performance so as to compete with low-cost and flexible commodity polymers; the blending with other natural polymers, such as thermoplastic starch (TPS), could represent a valid support to both obtain cost-effective biopolymeric-based systems and enhance biodegradability without compromising environmental and carbon management benefits, but reaching improved mechanical properties [14].

Starch, a completely biodegradable polysaccharide biosynthesized by numerous plants, like maize, wheat, potato, rice, pea, etc., is one of the most abundant renewable feedstock resources known to man. Thanks to its biodegradability, renewability, and easy availability, starch has been extensively studied as a low-cost component of biodegradable plastic materials. Chemically, starch is mostly composed of linear amylose and highly branched amylopectin, providing a native crystalline material. When mixed with some water and/or plasticizers such as glycerol, and following subjected to heat and shearing action, starch undergoes spontaneous destructurization. A homogeneous melt known as thermoplastic starch (TPS), evidencing typical thermoplastic behavior, is formed [15]. Hence, TPS can be obtained and formulated by means of standard equipment commonly used in industrial manufacturing of synthetic polymers. These processes include extrusion [16], compression molding [17], injection molding [18], and extrusion blowing [19]. However, this natural polymer has some drawbacks, such as high hydrophilicity and hygroscopicity, being responsible for high water 
vapor permeability, the quick aging effect due to the retrogradation process, and poor mechanical properties $[17,20]$. This is why blending with more hydrophobic polymers, such as PLA, could enhance its functional properties. Hence, the mixing of PLA and TPS would combine the advantages of the two polymers by synergizing their properties and contemporarily preserving the complete biodegradability of the blend. Further, the addition of TPS into a PLA matrix could also decrease the material cost and increase its biodegradation rate. Moreover, the addition of a compatibilizer able to improve their interfacial adhesion is an attractive option, and it could improve their mechanical and barrier properties, thus reducing both affinity with water and retrogradation with time [21]. To this aim, literature data reported different strategy approaches, like the incorporation of epoxidized soybean oil in blends of PLA and starch grafted with maleic anhydride, improving their mechanical properties [22], the addition of tung oil anhydride as a reactive plasticizer [22], coupling agent as methylene diphenyl diisocyanate [23], maleic anhydride to graft either on PLA [24] or starch [25]. Nevertheless, all these strategies could lead to the presence of unsafe reactive residues in the material, which should be tested as to their food safety.

Regarding epoxidized oils to improve PLA and TPS materials, several works reported the use of epoxidized soybean oil [26,27], epoxidized cardanol derivates [28], and epoxidized cottonseed oil [29].

Recently, epoxidized vegetable oils have attracted increasing attention due their renewability, availability at relatively low cost, and their potential in several industrial applications. Epoxidized soybean oil is the most important, with a global market of 328.8 kilotons in 2016 [30], and it is applied in the polyvinyl chloride (PVC) industry as a secondary plasticizer and stabilizer due its free radical scavanging properties. Epoxidized oils are generally prepared by reaction of unsaturations of oil with a peracid (perfomic or peracetic), obtained in situ for safety reasons, as reported by Santacesaria et al. [31]. Epoxidized oils were proposed as suitable plasticizers of also bio-based polymers, such as PLA poly (lactic acid), able to influence ductility of the material, measured as the ratio between the failure to yield strain [28]. Moreover, in order to solve the food and no-food debate, a particular issue for developing countries, alternative vegetable sources of oil were explored. The Cynara cardunculus cardoon plant has been recently reported as interesting biomass, native to the Mediterranean basin, growing on arid lands, as biorefinery feedstock [32]. This crop can be adaptable enough to grow on contaminated lands and polluted soils, and it can therefore be considered as a sustainable no-edible resource: Its economic and environmental sustainability lies in notable profits due to lower cultivation costs and its potential to produce roots with high inulin content and seeds with high yield of oil extraction, about $25 \%-30 \%$. The environmental sustainability of the Cardoon is plenty reported in the current literature [33], considering its ability to grow in dry lands of Mediterranean lands and its potential application in green chemistry. Regarding the content of oil in the seeds, it was depicted to be close to soybean and a sunflower $[32,34,35]$. As matter of fact, Turco et al. reported the epoxidation of cardoon seed oil, obtaining a product with quality properties similar to those of soybean. In particular, the epoxidized cardoon seed oil has been proposed for applications as a plasticizer of PLA, to overcome the bio-based polymer drawbacks and to improve the overall properties of biodegradable plastics for food packaging materials [32].

In this work, corn starch and poly (lactic acid) blends including cardoon epoxidized oil were produced by internal mixing and compression molding, in order to evaluate the effect of the oil on chemicophysical, mechanical, barrier properties, surface wettability, and spectral optical properties. The outcomes are discussed and compared with those of neat polymeric films, in order to widen and encourage the feasibility of PLA/TPS-based systems as potential bioplastics for food packaging applications. 


\section{Experimental Section}

\subsection{Material and Chemicals}

Corn starch ( $28 \%$ amylose) was provided by Roquette (Roquette Laisa, Benifaió, Spain), glycerol was obtained from Panreac Química, S.A. (Castellar del Vallès, Barcelona, Spain), and amorphous PLA 4060D, density of $1.24 \mathrm{~g} / \mathrm{cm}^{3}$, was purchased from Natureworks (Minnetonka, MN, USA).

Hydrogen peroxide (60 wt.\%) was kindly provided by Solvay Italia (Spinetta Marengo, Italy). Unless otherwise specified, all the other chemicals were purchased from Merck (Kenilworth, NJ, USA) and Sigma (Saint Louis, MO, USA) (analytical or reagent grade), and they were applied as received without purification or treatment.

The cardoon seed oil was recovered from a field experiment made in Acerra (Naples, Italy), a plain area of about $28 \mathrm{~m}$, characterized by dry and very warm spring-summers and by sandy loam soils (Clay $14.4 \%$, Silt $22.6 \%$, Sand $63.0 \%$ ), with a neutral $\mathrm{pH}$, and a content of $\mathrm{N}(0.2 \%)$ and organic matter $(2.6 \%)$. Oil was extracted with a mechanical press, with an operative capacity of $14 \mathrm{~kg} / \mathrm{h}$ and temperature regulated at $50^{\circ} \mathrm{C}$.

\subsection{Epoxidation Process}

Cardoon oil epoxidation was carried out in a jacketed glass reactor $(500 \mathrm{~mL})$, equipped with a thermocouple, a reflux condenser, and a mechanical stirrer $(750 \mathrm{rpm})$. The reaction mixture was heated at $65{ }^{\circ} \mathrm{C}$ and kept isothermal using a thermostat with re-circulating water into an external jacket. For the epoxidation of oil, the ortophosphoric acid (1.2 g), used as a catalyst, was placed into the reactor and mixed with the cardoon oil $(100 \mathrm{~g})$. The mixture was well stirred and heated at the desired reaction temperature. Afterwards, hydrogen peroxide ( $37 \mathrm{~g})$ and formic acid (5.38 g) were added by a syringe pump to keep the temperature constant. Then, the reaction mixture was stirred at $65^{\circ} \mathrm{C}$ for $3 \mathrm{~h}$. At the end of the reaction, the product was withdrawn from the reactor, quenched, and centrifugated at $3000 \mathrm{rpm}$ for $20 \mathrm{~min}$. The aqueous phase was separated from the organic phase, and the latter was treated with a solution of sodium bicarbonate $(5 \% \mathrm{wt})$ to neutralize all the residual acidity, then dried with anhydrous magnesium sulphate and finally analyzed to evaluate the iodine number (I.N.) in accordance with the Wijs method (ISO3961:2009) and the oxirane number (O.N.) (ASTM D1652-97) [36].

\subsection{Preparation of PLA-TPS-ECO Based Films}

Corn starch was blended with PLA in ratios of 80:20 and 20:80, glycerol was added at 30\% by weight with respect to starch, and the epoxidized oil was added at $3 \%$ by weight with respect to PLA fraction. Neat TPS and PLA films were used as the controls.

Specifically, the following blend compositions were prepared and coded: PLA80, in which the weight ratio PLA/TPS was 80/20, PLA80_ECO, in which the weight ratio PLA/TPS/ECO was 77/20/3, TPS80, in which the weight ratio TPS/PLA was 80/20, and TPS80_ECO where the mass ratio TPS/PLA/ECO was 80/17/3. The melt blending process was carried out in an internal mixer (HAAKE ${ }^{\mathrm{TM}}$ PolyLab ${ }^{\mathrm{TM}} \mathrm{QC}$, Thermo Fisher Scientific, Munich, Germany) at $140^{\circ} \mathrm{C}, 50 \mathrm{rpm}$, for $10 \mathrm{~min}$, and $50 \mathrm{~g}$ of blend were processed in each batch. The obtained pastes were cut into pellets and conditioned at $25^{\circ} \mathrm{C}$ and $53 \%$ relative humidity $(\mathrm{RH})$ for one week before the compression molding to obtain the films. To this end, a hot plate press (Model LP20, Labtech Engineering, Prakan, Thailand) was used. A total of $3 \mathrm{~g}$ of the conditioned pellets were placed onto Teflon sheets and preheated for $3 \mathrm{~min}$ at $140{ }^{\circ} \mathrm{C}$ and compression molded for $1 \mathrm{~min}$ at 30 bars, followed by $3 \mathrm{~min}$ at 130 bars; thereafter, a 3 min cooling cycle was applied. Films were conditioned at $25^{\circ} \mathrm{C}$ and $50 \% \mathrm{RH}$ for 1 week before their characterization.

\subsection{Attenuated Total Reflection Fourier Transform Infrared Spectroscopy (FTIR-ATR)}

Fourier transform infrared spectroscopy (FTIR) analysis was performed in ATR modality, on polymeric films with an averaged thickness of $50 \mu \mathrm{m}$. FTIR-ATR spectra were collected with 
a Perkin-Elmer Spectrum 100 spectrometer (Waltham, MA, USA). All the samples were analyzed at room temperature. Spectra were recorded as an average of 16 scans in a range of $4000-400 \mathrm{~cm}^{-1}$, with a resolution of $4 \mathrm{~cm}^{-1}$.

Spectroscopic manipulation, such as baseline adjustment and normalization, was done with OMNIC 9 software (Thermo Fisher Scientific, Inc., Waltham, MA, USA).

\subsection{ECO Mass Evaluation by Solvent Extraction of Oily Phase from Films and ${ }^{1} H-N M R$ (Nuclear Magnetic Resonance) Analysis}

A solvent extraction was carried out to recover the oil, evaluate mass, and exclude any migration process from the polymeric surface of films. The extraction was performed in accordance with the following procedure: About $2 \mathrm{~g}$ of the film were cut and placed in a $100 \mathrm{~mL}$ glass flask, then $25 \mathrm{~mL}$ of chloroform were added. The mixture was stirred until the PLA was completely dissolved (about 15-20 min at room temperature). The obtained suspension was filtered on $0.45 \mu \mathrm{m}$ PTFE filters in order to eliminate the starch fraction insoluble in chloroform. The permeate of the filtration, completely transparent, was added drop by drop into a becker containing cold hexane. Therefore, the formation of PLA white precipitate was observed. The latter was removed by simple filtration on buckner. Subsequently, the hexane derived by the filtration was transferred into a $250 \mathrm{~mL}$ calibrated flask, and the solvent was removed to a rotary evaporator, leaving an oily residue, the epoxidized cardoon oil. Both the PLA recovered from filtration on buckner and the oily residue were weighed and analyzed by ${ }^{1} \mathrm{H}-\mathrm{NMR}$ spectroscopic analysis, dissolving $15 \mathrm{mg}$ of sample in deuterated chloroform $\left(\mathrm{CDCl}_{3}\right)$.

\subsection{Scanning Electron Microscope (SEM)}

Morphological analysis of films was performed by a scanning electron microscope (SEM) (Quanta 200 FEG, 338 FEI, Eindhoven, Netherlands), on cryogenically fractured cross-sections. SEM measurements were collected at room temperature, internal water vapor pressure of $66.66 \mathrm{~Pa}$, high vacuum mode, an acceleration voltage of $20 \mathrm{kV}$ and using a large field detector (LFD). Cross-sections samples were fixed onto aluminum stubs using carbon adhesive. Before each observation, the surfaces were coated with a homogeneous layer $(18 \pm 0.2 \mathrm{~nm})$ of $\mathrm{Au}$ and Pd alloy by means of a sputtering device (MED 020, Bal-Tec AG, Tucson, AZ, USA).

\subsection{Differential Scanning Calorimetry (DSC)}

Differential scanning calorimetry measurements were performed using a Q2000 Tzero differential scanning calorimeter (DSC), TA Instrument (New Castle, DE, USA), equipped with a refrigerated cooling system (RCS).

The calorimeter was calibrated in temperature and energy with indium. Dry nitrogen was used as purge gas at a rate of $30 \mathrm{~mL} / \mathrm{min}$. Each sample was previously heated from 25 to $180{ }^{\circ} \mathrm{C}$ at a rate of $10^{\circ} \mathrm{C} / \mathrm{min}$ to erase previous thermal history. After a brief isotherm step of one minute in order to thermally stabilize the samples, non-isothermal crystallization experiments were performed by cooling the sheets up to $-20^{\circ} \mathrm{C}$ at a rate of $10{ }^{\circ} \mathrm{C} / \mathrm{min}$. After an isotherm of one minute at $-20^{\circ} \mathrm{C}$, a second heating run up to $250^{\circ} \mathrm{C}$ at $10{ }^{\circ} \mathrm{C} / \mathrm{min}$ was recorded. Before DSC measurements, the samples were dried under vacuum at room temperature for $24 \mathrm{~h}$. All the experiments were repeated three times to ensure reproducibility.

\subsection{Thermogravimetric Analysis (TGA)}

Thermogravimetric analyses (TGA) were carried out with a Mettler Toledo TGA/SDTA851e. Analyzer Mod. TG50 (Goldach, Switzerland). Measurements were performed on samples of about $8-10 \mathrm{mg}$, placed in open ceramic crucibles and heated from room temperature to $600{ }^{\circ} \mathrm{C}$ at $20^{\circ} \mathrm{C} / \mathrm{min}$ in nitrogen atmosphere, with a nominal gas flow rate of $30 \mathrm{~mL} / \mathrm{min}$. 


\subsection{Film Thickness}

The film thickness was measured using a digital micrometer (IP65 Mitutoyo, Kawasaki, Japan). The values were reported as the mean value of five different points measurements. These values were used to evaluate the mechanical and barrier properties.

\subsection{Mechanical Properties}

Tensile tests were carried out by a dynamometer model 4301, Instron (Canton, OH, USA) equipped with a load cell of $1 \mathrm{kN}$. The measurements were performed on dumbbell-shaped films. The width and the length of investigated films were respectively 4 and $28 \mathrm{~mm}$, while the thickness of each film measured as previously detailed was expressed as the average value $(0.2 \div 0.3 \mathrm{~mm}$. $)$. All the measurements were carried out at $25{ }^{\circ} \mathrm{C}$ and $50 \% \mathrm{RH}$, at a crosshead rate of $2 \mathrm{~mm} \cdot \mathrm{min}^{-1}$. The reported data were the average values of six measurements. Young's modulus, stress, and strain at break points were determined.

\subsection{Permeability Tests}

Water vapor transmission rate (WVTR) was measured according to the ASTM E96 (1993) wet method [37], using CEAST (Norwood, MA, USA) aluminum diffusion cell cups with a $6.154 \mathrm{~cm}^{2}$ exposed area. Cups were filled with distilled water $(\mathrm{RH}=100 \%)$ and placed in an environmental chamber set at a temperature of $25{ }^{\circ} \mathrm{C}$ and a relative humidity of $50 \%$. Each sample was firstly equilibrated for $48 \mathrm{~h}$ before measurements, then weighed each $24 \mathrm{~h}$. WVTR values, expressed in $\mathrm{g} /\left(\mathrm{h} \cdot \mathrm{m}^{2}\right)$, were determined from a linear plot of weight change vs. time, following the equation:

$$
\mathrm{WVTR}=\frac{\Delta G}{t \times A}
$$

where $\Delta G$ was the weight change (g), $t$ was the time during which $\Delta G$ occurred (h), $A$ was the test area cell cup $\left(\mathrm{m}^{2}\right)$, and $\Delta G / t$ was the slope of linear plot. Water vapor permeability (WVP) was calculated according to the following equation:

$$
\mathrm{WVP}=\frac{\mathrm{WVTR} \times T h}{\Delta P}
$$

where $T h(\mathrm{~m})$ was the thickness of the films and $\Delta P$ was the water pressure difference between both sides of the film $(\mathrm{Pa})$. Data were the mean of three measurements for each sample.

Oxygen permeability tests were performed by means of an Extra Solution Multiperm instrument, produced by Extra Solution Pieve Fosciana (LU), Italy. The permeabilizer is equipped with a coulometric sensor and characterized by an accuracy ranging between 0.01 and $7500 \mathrm{~cm}^{3} / \mathrm{m}^{2} \times 24 \mathrm{~h} \times$ bar. Before measurements, the instrument was calibrated with PET Standard films of two different thicknesses: 20 and $100 \mu \mathrm{m}$, provided by the manufacturer. The measurements were performed at $25{ }^{\circ} \mathrm{C}$ and $50 \%$ relative humidity (RH), under $30 \mathrm{~mL} / \mathrm{min}$ of nitrogen gas flow. The instrumental apparatus consists of a double chamber diffusion cell. The film was inserted between the two chambers: Oxygen enters the lower one, and a dry nitrogen flux flows in the upper one. A zirconium oxide sensor detects the oxygen diffusion across the film. The exposed area of the film was $50 \mathrm{~cm}^{2}$. Collected data were converted in oxygen transmission rate (OTR), that is, the time rate of oxygen flow between two parallel surfaces under steady conditions at specific temperature and RH. Oxygen permeability $\left(\mathrm{O}_{2} \mathrm{P}\right)$ was calculated from $\mathrm{O}_{2} \mathrm{TR}$ data by means of the following equation:

$$
\mathrm{O}_{2} \mathrm{P}=\frac{\mathrm{O}_{2} \mathrm{TR} \times T h}{\Delta P}
$$

where $\mathrm{O}_{2} \mathrm{TR}$ is oxygen transmission rate and $T h$ and $\Delta P$ are the averaged thickness and water pressure difference between both sides of the film at $25^{\circ} \mathrm{C}$ and $\mathrm{RH}=50 \%$, respectively. 


\subsection{Surface Wettability: Water Contact Angle Measurements}

Surface-free energy and water contact angle measurements were performed on neat PLA and PLA-based films. An optical contact angle device, Drop Shape Instruments FTA1000 (Portsmouth, VA, USA), equipped with a high-resolution video camera $(752 \times 582$ pixels and image acquisition speed equal to 25 frames per second), was used, and the data were analyzed by KRUSS software (RTA 32). The static contact angle of water at room temperature $(\theta, \mathrm{deg})$ was measured by a sessile drop method by dropping 11 drops of distilled water $(2 \mu \mathrm{L})$ onto the surface film using a syringe. The entire droplet was released from $0.5 \mathrm{~cm}$ above the polymer surface to ensure the consistency of the measurements. The contact angle was calculated immediately after droplet deposition by means of the angle between the baseline of the drop and the tangent. For each sample, contact angle measurements were taken and averaged from 5 different directions, including parallel and perpendicular. The detections were performed at a stabilized condition of $25^{\circ} \mathrm{C}$ and $50 \mathrm{wt} . \%$ relative humidity.

\subsection{UV/VIS Spectral Characterization of the Films}

Spectral characterization of the films was performed using the UV/VIS Spectrophotometer JASCO V-650 (accuracy $0.5 \mathrm{~nm}$, range 190-850 nm, Oklahoma, OK, USA). The component of the transmittance perpendicular to the films (normal transmittance) was measured using the standard configuration of the system. Total transmittance as well as total reflectance were achieved using the integrating sphere JASCO ISN-722 (inside diameter $60 \mathrm{~mm}$, range 200-870 nm).

\section{Results and Discussion}

\subsection{Epoxidation Process}

Following the procedure described in the experimental section, the cardoon seed oil was suitably epoxidized, obtaining a product with properties (I.N. $=11 \mathrm{gI}_{2} / \mathrm{g}$ sample) O.N. $=6 \mathrm{gO}_{2} / \mathrm{g}$ sample) close to market quality. The epoxidized cardoon oil thus produced was used to prepare the blends above reported.

3.2. Structural, Quantitative and Morphological Analyses: Attenuated Total Reflection Fourier Transform Infrared Spectroscopy (FTIR-ATR), ECO Mass Evaluation, Nuclear Magnetic Resonance Spectroscopy $\left({ }^{1} H-N M R\right)$, Scanning Electron Microscopy (SEM)

FTIR spectroscopy was performed in ATR modality due to the high thickness of the samples. As far as neat TPS, PLA, PLA80m and PLA80_ECO are concerned, FTIR-ATR spectra are reported in Figure 1a-c.

In particular, in Figure 1a, TPS and glycerol main stretching vibrations are reported. Due to their similar absorption groups, most of the peaks overlap; specifically, in the range of $1500-700 \mathrm{~cm}^{-1}$, both CH bending (1500-1200) and CO stretching (1200-900 $\mathrm{cm}^{-1}$ ) were observed. At $1648 \mathrm{~cm}^{-1}$, a weak band related to $\mathrm{OH}$ bending, typical of starch bound water, could be detected, whereas in the region between 3300 and $2900 \mathrm{~cm}^{-1}$, a wide stretching absorption of hydrogen bonding $\mathrm{OH}$ and both starch and glycerol $\mathrm{CH}$ stretching were found. Similar results were found by Kizil et al. [38]. In neat PLA, peaks at 2992 and $2952 \mathrm{~cm}^{-1}$ were related to $\mathrm{CH}$ asymmetric and symmetric stretching vibration, respectively (not reported). As usually occurring in semicrystalline polyesters, the stretching band of carbonyl group (-COO-) was composed of two overlapping peaks, often discernible following a deconvolution (not reported) [39].

In neat PLA (Figure 1b), it is possible to detect a relatively broad band cantered at approximately $1776 \mathrm{~cm}^{-1}$, occurring as a shoulder of a sharper and more intense band at about $1746 \mathrm{~cm}^{-1}$. Previous studies showed that the above mentioned peaks arise from the amorphous regions and crystalline domains of ester carbonyl groups stretching of the polymer, respectively.

The $-\mathrm{CH}_{3}$ bending vibration was found at $1450 \mathrm{~cm}^{-1}$, whereas $-\mathrm{CH}$ symmetric and asymmetric deformations could be found at 1382 and $1359 \mathrm{~cm}^{-1}$. The peaks found at 1127, 1090, and $1042 \mathrm{~cm}^{-1}$ 
corresponded to $\mathrm{C}-\mathrm{O}$ stretching vibration. Finally, in the fingerprint region, two bands at 868 and $755 \mathrm{~cm}^{-1}$ were related to $\mathrm{C}-\mathrm{C}$ stretching vibration of, respectively, amorphous and crystalline phase of PLA [40].

In general, spectroscopy is a reliable tool to investigate the physical and chemical interactions between components in polymeric-based systems [41]. In the investigated system, it was worth underscoring the kind of specific interaction occurring between PLA and epoxidized oil (ECO). Finalized to understand if during the thermoprocessing of the samples, extrusion, and compression molding, some reaction inducing the opening of epoxidized ring occurred, a comparison between PLA80_ECO and PLA80 spectra, was performed. Unfortunately, most of the vibration frequencies typical of epoxidized oil, in the fingerprint region of the spectrum, were not detectable since they were weak, broaded, and covered up by PLA main vibrational peaks (spectra not reported) [32]. Nevertheless, by means of a spectral subtraction between PLA80_ECO and PLA80 spectra reported in Figure 1c, it was possible to highlight the typical stretching $\mathrm{C}-\mathrm{H}, \mathrm{C}-\mathrm{O}-\mathrm{C}, \mathrm{C}-\mathrm{O}$, and $\mathrm{C}-\mathrm{O}-\mathrm{C}$ of epoxidized cyclic ether at 720, 820, 930, and $1150 \mathrm{~cm}^{-1}$, respectively.
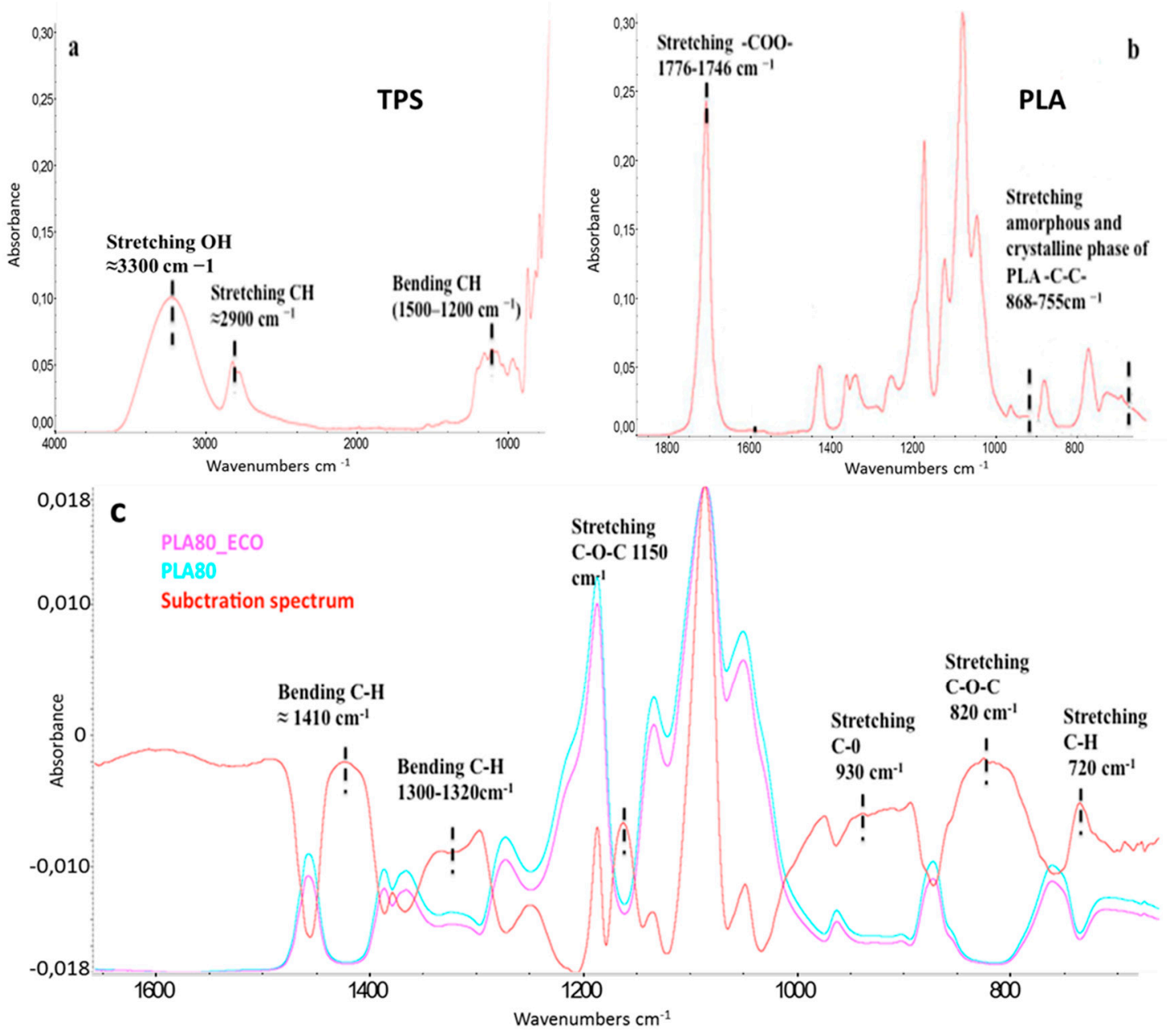

Figure 1. FTIR-ATR of (a) neat thermoplastic starch (TPS), (b) neat poly (lactic acid) (PLA) (a,b main absorption peaks), (c) carbonyl and fingerprint regions of PLA80_ECO (pink curve), PLA80 (azure curve), and their spectral subtraction (red curve) in a magnified absorbance scale.

Moreover, TPS and glycerol C-H bending, in the range of 1300 and $1400 \mathrm{~cm}^{-1}$, was noticeable too. This finding confirmed that a fraction of ECO was still present inside the blend. Finalized to know the effective amount of epoxidized cardoon oil in PLA80_ECO polymeric system, a solvent extraction was performed, following the procedure detailed in the experimental part. A mass corresponding to $3 \%$ in 
weight of oil with respect to PLA was recovered. This weight corresponded to the starting amount of ECO introduced inside the blend. A further confirmation that the oily fraction recovered from the bulk was exactly ECO and not a reaction product of the same with some hydrolyzed PLA, was provided via nuclear magnetic resonance spectroscopy $\left({ }^{1} \mathrm{H}-\mathrm{NMR}\right)$, carried out on both neat and post-processed PLA (spectra not reported), and neat ECO and recovered oily fraction, (Figure 2). The perfect overlapping of both ${ }^{1} \mathrm{H}-\mathrm{NMR}$ spectra corroborated that no PLA hydrolysis or thermal depolymerization occurred and that the recovered oil was exactly the epoxidized one.

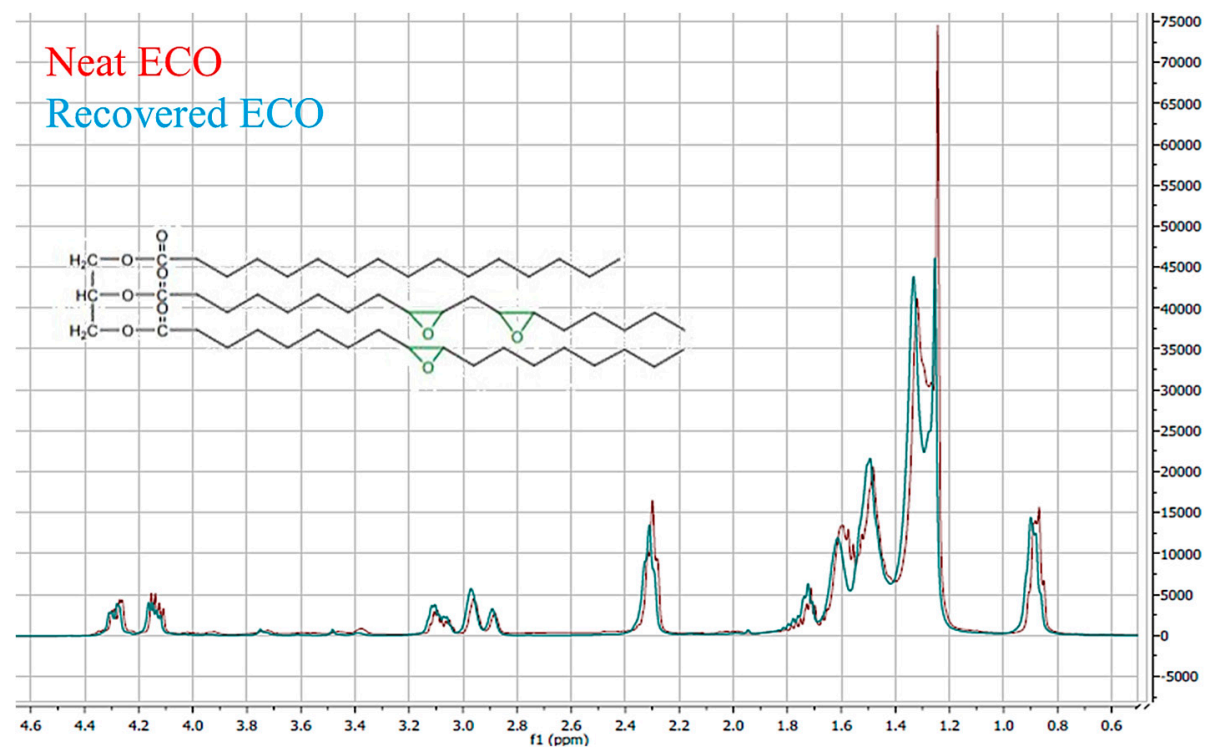

Figure 2. ${ }^{1} \mathrm{H}-\mathrm{NMR}$ overlapping spectra of: neat ECO (red) and recovered oily fraction (azure curve).

These outcomes pointed out significant information. Indeed, from the full recovery of the structurally unmodified oil, no reactive processing occurred during the thermal treatments of the polymeric blends [42], thus confirming both the pure plasticization action of ECO and its physical interaction preferably with the hydrophobic fraction of PLA80_ECO blend, since it was wholly found only in a PLA polymeric matrix. It is plausible that hydrogen bonding could occur between the ether oxygen of epoxidized ring and PLA polar residues. Moreover, it is worth highlighting that the extractive oil method represented a valid alternative to the migration tests, usually performed by periodically weighing the samples after thermal treatment in the oven at $135^{\circ} \mathrm{C}$ [43]. On the other hand, in the investigated system, the presence of TPS could mislead and invalidate the usual migration test due to its high hydrophilicity. Indeed, the weight decrease following thermal treatment could be likely due to water evaporation in addition to the oil diffusion and desorption. As a matter of fact, since all the oil was recovered after about six months from the film preparation, it is possible to claim that no exudation and migration phenomena occurred, in this way confirming the good oil embedding in between PLA macromolecular chains. This outcome is particularly interesting since in most similar investigated systems, exudation and migration oil effects represent a serious drawback, limiting the potential application of the films. Concerning TPS80_ECO, it was not possible to proceed to the oil extraction and recovery; in fact, only $20 \%$ in weight of PLA was introduced in TPS80_ECO formulation, and ECO was $3 \% w / w$ of PLA weight. This unsubstantial mass was well below the de minimis threshold of the extractive method sensitivity used. It is well known that macroscopic properties, such as mechanical and barrier performances of polymer blends, are strongly related to their morphology, as reported by several authors [44,45].

Relative to the investigated system, morphological analysis was performed, and information related to the interaction between the hydrophilic TPS and the hydrophobic PLA could be found strictly affected by their interfacial adhesion [46]. 
In Figure 3a,b, the micrographs of cryogenically fractured cross-sections of neat PLA (Figure 3a) and TPS (Figure 3b) are reported. As shown in Figure 3a, neat PLA showed an uneven and rough fracture surface, due to its brittle nature.
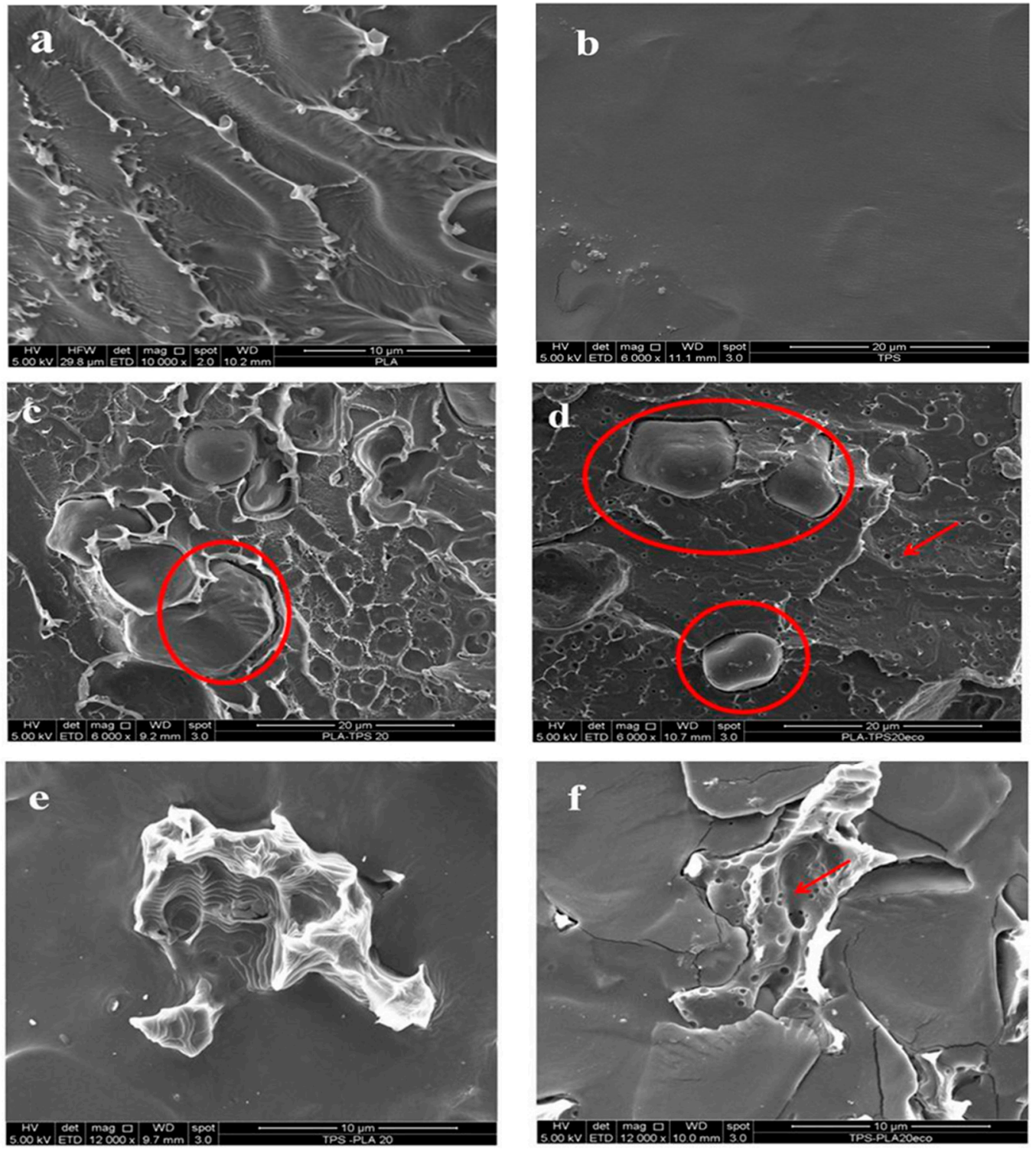

Figure 3. Cross-sectional surface SEM micrographs of neat PLA (a), neat TPS (b), PLA80 (c), PLA80_ECO (d), TPS80 (e), and TPS80_ECO (f), respectively.

The pure thermoplastic starch film (Figure 3b) showed the reduction of starch granules after processing, demonstrating the extrusion process improved the gelatinization of the native starch granules. As far as the blends are concerned, in Figure 3c-f, the micrographs of PLA80, PLA80_ECO, TPS80, and TPS80_ECO are reported. From the analysis of all the blend micrographs, it is possible to emphasize the phase separation between the two polymers, as expected from immiscible polymers, as widely reported in literature [47]. The phase separation is related to the lack of affinity between TPS and PLA [48]. PLA is a hydrophobic polyester, whilst TPS is a highly hydrophilic polysaccharide. In particular, in a PLA rich phase system (Figure 3c), a heterogeneous surface topography was observed, in which a high concentration of micrometric deep coarsened interstitial cavities generally appeared as spherical polymeric microstructure domains in which TPS particles were implanted. Regardless, TPS particles were not uniformly dispersed in the matrix, and it was also possible to highlight some sporadic 
dark voids owing to the TPS particles debonding phenomenon, occurring during the cryogenic film surface delamination (red circles), which could be ascribed to the high interfacial tension between the hydrophilic polymer and the hydrophobic one. When the epoxidized cardoon oil was included inside the blend (Figure 3d), a sort of plastic deformation occurred, associated with shear-yield fracture and absence of brittle cracks of the surface. Therefore, a lean improvement of the interfacial adhesion between PLA and TPS fracture surfaces took place, evidenced by smoothed and fine separation domains. Probably, the ECO effect was to plasticize the blend, in particular, PLA, by increasing the free volume and the polymer chain mobility and decreasing interchain interaction; consequently, a better dispersion of TPS was allowed. Moreover, it is plausible that the epoxidized oil bridged some interaction between poly (lactic acid) chain ends and hydroxyl groups in thermoplastic starch, thus leading to a slight compatibilization effect. This outcome was reflected in improved ductile-flexible properties of PLA in PLA80_ECO blends, as detailed below; similar results were found by Ferri et al. (2016) [49].

From the analysis of Figure 3d, it is possible to observe some microvoids, likely due to the oil evolution occurring during the cryogenic fracture. The micrographs related to the TPS rich phase, TPS80 and TPS80_ECO, are reported in Figure 3e,f, respectively. Even in these systems, it is possible to highlight a marked phase separation; PLA microdomains were completely immiscible with the hydrophilic polymeric matrix in both blends [46]. Moreover, no substantial difference was observed between the micrograph due to the low amount of plasticizer. Regardless, from Figure 3f, it was possible to observe the presence of very small holes due to the evolution of oil from the PLA matrix. This outcome confirmed the previous hypothesis related to the specific interaction occurring between PLA and ECO. Finally, apart from the pulling out phenomenon of PLA from the TPS rich phase, it is worth evidencing the smoothed, regular, and homogeneous TPS polymeric matrix, typical of a plastic and amorphous polymer.

\subsection{Thermogravimetric Analysis (TGA)}

TGA thermograms of the samples and their first derivative curves (DTG) are reported in Figure 4a,b, whereas the main thermal parameters, detectable from DTG curves, are summarized in Table 1.

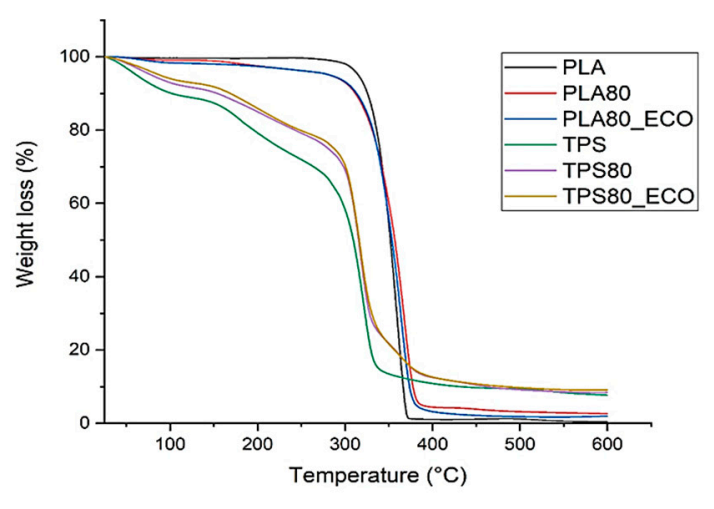

(a)

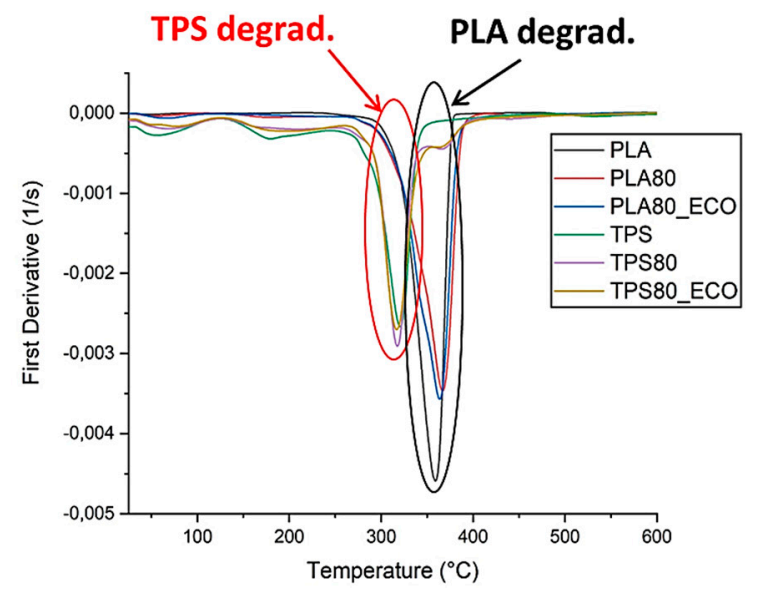

(b)

Figure 4. TGA (a) and derivative (DTG) (b) curves of PLA- and TPS-based blends. 
Table 1. Thermal parameters of PLA- and TPS-based blends from TGA analysis.

\begin{tabular}{cccccc}
\hline Data/Samples & $\boldsymbol{T}_{\text {onset }}\left({ }^{\circ} \mathbf{C}\right)$ & $\begin{array}{c}\boldsymbol{T}_{\text {lossH2O }}\left({ }^{\circ} \mathbf{C}\right) \\
\text { Weakly Bound }\end{array}$ & $\begin{array}{c}\boldsymbol{T}_{\text {lossH2O }}\left({ }^{\circ} \mathbf{C}\right) \\
\text { Strongly Bound }\end{array}$ & $\begin{array}{c}\boldsymbol{T}_{\text {decomp }}\left({ }^{\circ} \mathbf{C}\right) \\
\text { Glycerol }\end{array}$ & $\boldsymbol{T}_{\text {peak }}\left({ }^{\circ} \mathbf{C}\right)$ \\
\hline PLA & 290 & - & - & - & 360 \\
PLA80 & 280 & - & - & - & 367 \\
PLA80_ECO & 275 & - & - & - & 365 \\
TPS & 260 & $25<\mathrm{T}<80$ & $80<\mathrm{T}<180$ & $200<\mathrm{T}<260$ & 320 \\
TPS80 & 280 & $25<\mathrm{T}<80$ & $80<\mathrm{T}<180$ & $200<\mathrm{T}<260$ & 318 \\
TPS80_ECO & 280 & $25<\mathrm{T}<80$ & $80<\mathrm{T}<180$ & $200<\mathrm{T}<260$ & 318 \\
\hline
\end{tabular}

From the analysis of the thermograms, normalized with respect to starting sample weights (Figure 4a), it is possible to observe that PLA-based systems were more thermally stable. In particular, PLA followed a faster degradative kinetics, whereas PLA80 and PLA80_ECO evidenced a fair widening of the weight dropping down profile, emphasizing a better physical interaction between the polymeric components and epoxidized oil, at molecular level [50,51].

In addition, from the DTG curves (Figure $4 b$ ), it is worth noting that PLA slightly influenced the TPS degradative pattern, in somewhat shifting its thermal kinetics profile towards higher temperatures, as evidenced by the maximum degradation peak ( $T_{\text {peak }}$ ) (see Table 1 ). The epoxidized cardoon oil slightly anticipated the onset of PLA degradation; this outcome could be explained considering the plasticization effect of ECO; the increase of free volume made PLA more susceptible to thermal degradation. As concerns TPS-based films, it deserves mention that degradation took place in several steps, as detectable from thermograms and Table 1.

The first weight losses were due to the weak (ranging between $25-70{ }^{\circ} \mathrm{C}$ ) and strong (ranging between $70-180^{\circ} \mathrm{C}$ ) bound water evolution [52]. The following thermal degradation occurred at the expense of glycerol, ranging from 200 to $260^{\circ} \mathrm{C}$ and starch $\left(T_{\text {peak }}=320\right)$ [16]. By comparing the decomposition profiles of PLA- and TPS-based systems (DTG curves Figure 4b), it was interesting to highlight that in TPS80 and TPS80_ECO films, the degradation kinetics of TPS (red circle) and PLA (black circle) followed two separated outlines, thus confirming the phase separation of the two polymers.

\subsection{Differential Scanning Calorimetry (DSC)}

Usually, the thermal history of materials is erased by the first thermal scanning on DSC, and DSC curves coming from the second heating are considered. In the specific system, both PLA and TPS were amorphous polymers, as previously detailed, less than some PLA residual crystallinity resulting from its thermal processing. For this reason, it was suitable to investigate the first heating run in order to evaluate effective TPS Tg, strongly influenced by the presence of water and glycerol as plasticizers. As a matter of fact, the Tg is an important parameter; indeed, beneath the glass-transition temperature, the intermolecular bonds of macromolecular structure are strong, due to the small range left for Brownian movement, as is stated by Eyrings' 'free volume theory' [53]. At the Tg, the physical cohesive forces decrease drastically, the polymer expands, and the free volume increases to such an extent that there is space for migration of segments of about 20 to 40 monomer units [54].

As concerns the investigated system, in Figure $5 a, b$, the thermograms of the first and second runs are reported, respectively. In Figure $5 \mathrm{a}$, in addition to the weak melting phenomena associated with PLA $\alpha$ and $\alpha^{\prime}$ crystalline organizations and not found in the second heating ramp, it was possible to observe PLA Tg in PLA-based blends, whereas broad endothermic peaks associated with water evolution, which covered TPS Tg signals, were evidenced in TPS-based films [52]. As a matter of fact, from the analysis of the second heating, in Figure $5 b$, it was possible to evidence PLA and TPS Tg values. Regardless, the high glass transition temperatures of starch were misleading due to the absence of water as plasticizer. For this reason, DSC analyses were performed in hermetically sealed pans. In this way, the evaporation of water was hampered and the real TPS Tg was evaluated, as shown 
in Figure $5 \mathrm{c}$ and detailed in Table 2. From the analysis of data, the physical interactions occurring between the amorphous polymers could be discernible. In addition, the effect of epoxidized oil as further plasticizer was highlighted. In particular, the rich PLA phase films, PLA80 and PLA80_ECO, evidenced a considerable reduction of PLA Tg of about $5{ }^{\circ} \mathrm{C}$, since both TPS and oil could increase the free volume of PLA macromolecular chains. Nevertheless, no modification of TPS Tg could be observed, as expected, being the minor phase of the system. In TPS rich phase blends, TPS Tg increased by about $16^{\circ} \mathrm{C}$ in TPS80, due to the contribution of more rigid PLA macromolecular chains, and by about $13{ }^{\circ} \mathrm{C}$ in TPS80_ECO, due to the slight contribution of ECO as a plasticizer. The effect of TPS and ECO was also found in the melting of PLA residual crystalline fractions. The PLA used was an amorphous polymer, as previously indicated in materials and methods; hence, in the first heating run, two weak post-process melting phenomena, associated with $\alpha$ and $\alpha^{\prime}$ crystalline fractions, could be detected. The low $\triangle H m$ associated with melting phenomena slightly increased in PLA80 and PLA80_ECO systems (see Table 2 and Figure 5d), due to the plasticization effects of both TPS and ECO [55].
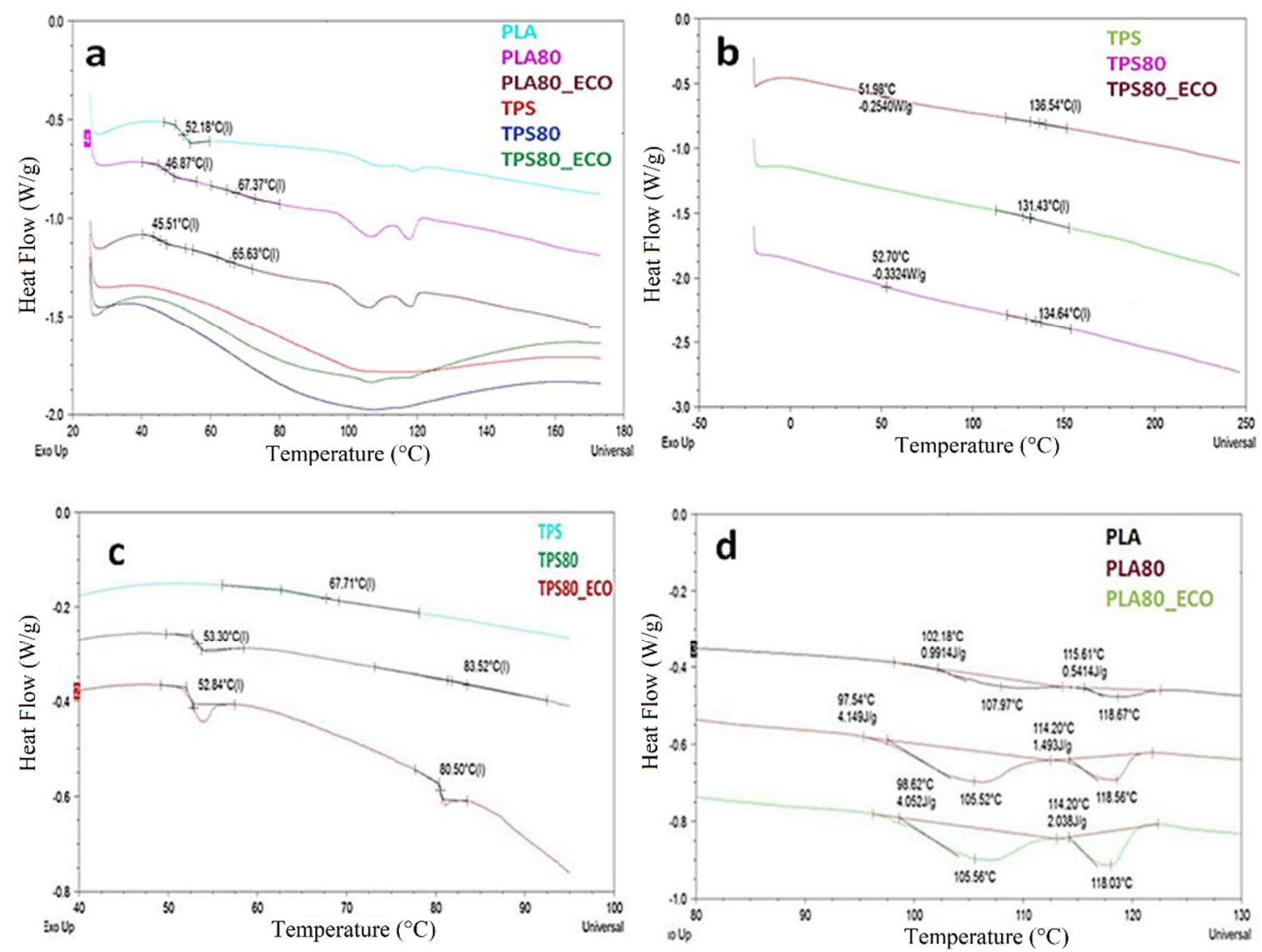

Figure 5. First thermal run (a,d) and second heating run (b). Heating run in hermetic sealed pan (c).

Table 2. Thermal parameters of PLA- and TPS-based blends from differential scanning calorimetry (DSC) analysis.

\begin{tabular}{cccccc}
\hline Samples/Data & Tg PLA $\left({ }^{\circ} \mathrm{C}\right)$ & $\operatorname{Tg}$ TPS $\left({ }^{\circ} \mathrm{C}\right)$ & $\Delta \boldsymbol{H}_{m}(\mathrm{~J} / \mathbf{g})$ & $\boldsymbol{T}_{m} \boldsymbol{\alpha}\left({ }^{\circ} \mathrm{C}\right)$ & $\boldsymbol{T}_{m} \boldsymbol{\alpha}^{\prime}\left({ }^{\circ} \mathrm{C}\right)$ \\
\hline PLA & 52 & - & 1.5 & 108 & 119 \\
PLA80 & 47 & 67 & 5.6 & 105 & 118 \\
PLA80EECO & 45 & 65 & 6.1 & 105 & 118 \\
TPS & - & 67 & - & - & - \\
TPS80 & 53 & 83 & - & - & - \\
TPS80_ECO & 53 & 80 & - & - & - \\
\hline
\end{tabular}


Nevertheless, no PLA melt crystallization during cooling (thermogram not reported) and further crystallization and melting processes in the second heating occurred, thus confirming the amorphous nature of the polyester [56]. In conclusion, at a molecular level, although two different $\mathrm{Tg}$ were always discernible in all the blends, a weak partial miscibility of the polymers could be ascertained due to the reciprocal variation of their Tg values [57]. As is already known, the thermal behavior of the polymers is reflected in macroscopic properties, such as mechanical performances, discussed below.

\subsection{Mechanical Properties (Tensile Test)}

Tensile properties of the samples are detailed in Table 3. From the analysis of data, it is worth notinf that the elastic modulus of all the samples followed the "rule of mixtures"; indeed, the addition of a more flexible and ductile polymer, as TPS, to a more rigid one like PLA, decreased Young's modulus of the latter [58]. The effect was particularly emphasized in the presence of the plasticizer, due to the increase of macromolecular chain mobility, particularly enhanced in PLA-based systems, due to the higher physical affinity between the polymer and the epoxidized oil, as previously discussed. By contrast, the addition of a rigid and though polymer like PLA to a more ductile one like TPS increased the elastic modulus of the latter; moreover, no plasticization effect was observed in TPS80_ECO, due to the low amount of the epoxidized oil.

Table 3. Mechanical properties of PLA- and TPS-based blends.

\begin{tabular}{cccc}
\hline Sample/Data & Young Modulus (MPa) & Stress at Break (MPa) & Strain at Break (\%) \\
\hline PLA & $1329 \pm 25$ & $50.5 \pm 4.7$ & $4 \pm 0.5$ \\
PLA80 & $1285 \pm 33$ & $27.4 \pm 0.8$ & $3.1 \pm 0.7$ \\
PLA80_ECO & $1135 \pm 31$ & $24.4 \pm 0.5$ & $4.6 \pm 0.5$ \\
TPS & $77 \pm 15$ & $5.4 \pm 0.9$ & $51 \pm 3$ \\
TPS80 & $150 \pm 15$ & $5.5 \pm 0.7$ & $19 \pm 4$ \\
TPS80_ECO & $158 \pm 12$ & $3.6 \pm 0.5$ & $7 \pm 1.2$ \\
\hline
\end{tabular}

Since the tensile strength of TPS is much lower than that of pure PLA, the tensile strengths of all blends were lower than that of pure PLA, showing a negative deviation from the rule of mixtures due to the incompatibility and separation phase between the polymers. The effect was particularly marked in TPS-based blends, where the tensile strength did not change at all. In fact, no physical entanglements occurred between the polymers due to their immiscibility; hence, when macromolecules underwent an applied external stress, they moved in the direction of the force by opposing a weak tensile strength; regardless, the absence of a plastic behavior caused the breaking of the samples at very low elongations; this outcome was particularly accentuated in PLA-based systems, due to the brittle nature of the polymer. Reduction of elongation at break by addition of more than $10 \mathrm{wt} . \%$ of TPS was previously reported [44]. Hence, in the investigated blends, the phase separation between the polymers was responsible for the mechanical properties dropping down.

\subsection{Water Vapor and Oxygen Permeability}

In semicrystalline polymers, small molecules diffusion occurs only through the amorphous phase, whereas the crystalline fraction does not contribute to permeability. This means that the permeability values are functions of the amorphous volumetric fraction. As far as investigated poly (lactic acid)/thermoplastic starch films are concerned, it is possible to assert that both polymers provided wide water and oxygen diffusion pathways, since both of them are amorphous. Hence, the different permeability values could be generally ascribed to the diverse diffusion $(D)$ and solubility $(S)$ coefficients, as permeability $P$, and can be expressed as the product of the solubility coefficient $S$ and the diffusion coefficient $D$ :

$$
P=D \times S
$$


Water vapor permeability values of all films are reported in Table 4 . The values of permeability were normalized with respect to the thickness of the samples. All the measurements were characterized by a dynamic nonsteady-state region, associated with the progress of the concentration profile across the thickness, and mainly determined by the diffusion coefficient, as laid down from ASTME96. From the analysis of data, it is possible to observe that the barrier properties of PLA80 film worsened due to the presence of hydrophilic TPS polymer, as expected. Indeed, the hydroxyl polar groups of both starch and glycerol were responsible for higher interaction with water molecules, thus favoring their diffusion in between the macromolecular structure; moreover, the high concentration of glycerol, as a plasticizer, enhanced the intermolecular chain distance, improving the macromolecular mobility, thus fostering the solubility of molecules and making the pathway of their diffusion easier, with the consequent increase of the transport parameters; similar results were reported by other authors working with hydrophilic polymers plasticized with polyols $[20,59,60]$. This effect was particularly enhanced in the binary blend; indeed, WVP was a result of a balance between the hydrophilic and hydrophobic character of the blend components and their interfacial properties. The greater the tension at the interface (less compatible blends), the greater the spaces between the phases, which favored water diffusion.

Table 4. Water vapor permeability (WVP), oxygen permeability $\left(\mathrm{O}_{2} \mathrm{P}\right)$, diffusion coefficient (D), solubility coefficient (S) measured at $25^{\circ} \mathrm{C}$ and $50 \%$ relative humidity, contact angle $(C A)$, and surface tension (ST) of PLA/TPS-based films.

\begin{tabular}{ccccccc}
\hline Samples & WVP $(\mathbf{n g} / \mathbf{m} \cdot \mathbf{P a} \cdot \mathbf{s}) \times \mathbf{1 0 ^ { - 3 }} \pm \mathbf{1 0} \%$ & $\mathbf{O}_{\mathbf{2}} \mathbf{P}\left(\mathbf{c m}^{\mathbf{3}} / \mathbf{m} \cdot \mathbf{s} \cdot \mathbf{P a}\right)$ & $\mathbf{D}\left(\mathbf{m}^{\mathbf{2}} / \mathbf{s}\right) \times \mathbf{1 0}^{-\mathbf{6}}$ & $\boldsymbol{S}\left(\mathbf{c m}^{\mathbf{3}} / \mathbf{m}^{\mathbf{3}} \cdot \mathbf{P a}\right)$ & $\boldsymbol{C A}(\mathbf{d e g})$ & $\boldsymbol{S T}(\mathbf{d y} / \mathbf{c m})$ \\
\hline PLA & 0.025 & $23.3 \pm 6.7 \times 10^{-1}$ & $2.2 \pm 2.6 \times 10^{-7}$ & $0.12 \pm 0.01$ & $73 \pm 2$ & $45 \pm 5$ \\
PLA80 & 0.11 & $61.1 \pm 1.7$ & $2.2 \pm 3.1 \times 10^{-7}$ & $0.32 \pm 0.01$ & $64 \pm 3$ & $58 \pm 3$ \\
PLA80_ECO & 0.038 & $23.4 \pm 6.7 \times 10^{-1}$ & $4.0 \pm 1.6 \times 10^{-7}$ & $0.07 \pm 0.0013$ & $60 \pm 2$ & $74 \pm 2$ \\
TPS & 1.3 & - & - & - & - & - \\
TPS80 & 1.1 & - & - & - & - & - \\
TPS80_ECO & 1.0 & - & - & - & - & - \\
\hline
\end{tabular}

In the PLA80_ECO blend, it is valuable to highlight that permeability decreased below the PLA WVP value, thus emphasizing the barrier effect exploited by the blend in the presence of epoxidized oil. Probably, as previously evidenced by morphological analysis, the epoxidized oil improved the interfacial adhesion between the polymeric matrix and dispersed phase, thus lowering both starch surface tension and the interspace between macromolecular chains, responsible for the hastening of water molecules diffusion. Moreover, being oily, ECO hindered water molecules' solubility; as a result, it provided a successful physical barrier to WVP. This outcome deserves particular attention, since a low concentration of epoxidized oil in a PLA rich phase system is able to drastically reduce water permeability.

In a TPS-based system, WVP was significantly higher, and no ECO effect was found due to its low concentration with respect the polymeric matrix.

In Table 4 , the values of $\mathrm{O}_{2} \mathrm{P}$, diffusion coefficient $(D)$, and solubility coefficient $(S)$ of PLA-based films measured at $25{ }^{\circ} \mathrm{C}$ and $50 \%$ relative humidity are reported. The values of permeability were normalized with respect to the thickness of the samples. All the measurements were characterized by a dynamic nonsteady-state region and a steady-state region. The former is associated with the progress of the concentration profile across the thickness and is mainly determined by the diffusion coefficient. The steady-state regime is related to a constant concentration of the permeant (curves not reported). From the steady state region, the permeability coefficients $\left(\mathrm{O}_{2} \mathrm{P}\right)$ were calculated [61]. Diffusion coefficients $(D)$ were obtained using the following equation [62]:

$$
D=\frac{L^{2}}{6 \theta}
$$

with $L$ being the thickness of the film. The time lag, $\theta$, was obtained by extrapolation from the integral curves of the experimental oxygen flux signals versus time [63]. 
From the analysis of table, it is possible to highlight the worthy increase of oxygen permeability in the PLA 80 blend mostly occurring at the expense of solubility coefficients; this outcome was expected due to the increase of accessible polymeric volume of starch fraction. Regardless, when the PLA80_ECO blend was investigated, an opposite trend was observed; indeed, the permeability decreased. Moreover, a drastic decrease of the solubility coefficient was detected, too. In this case, the presence of oil reduced the gas solubility due to both the lessening of accessible polymer matrix volume and the tightened structure formed by PLA and epoxidized oil. Indeed, the physical interaction, by means of hydrogen bonding, created a physical hindrance to the absorption and consequent oxygen molecules' solubility (Persico et al., 2009; Russo, Abbate, Malinconico, and Santagata, 2010). Data reported in Table 4 matched well with the results of permeability tests performed on PLA7000D films performed in the same experimental parameters [64] Differently from WVP, it was not possible to evaluate oxygen permeability for TPS-based films, since in this case, the thicknesses of the films were not homogeneous, and no reliable and reproducible results could be obtained.

\subsection{Surface Wettability: Water Contact Angle Measurements}

The value of contact angle and wettability of PLA-based blends is summarized in Table 4 .

As the surfaces of the films were not completely homogeneous, the measurements of the contact angle were made on three different points of solid surface. For the neat PLA, a contact angle of $73^{\circ}$ was found, and this value decreased with adding both TPS and epoxidized cardoon oil. This reduction for PL80 and PL80_ECO can be attributed to the presence of polar groups both in TPS and in ECO, hydroxyl and oxirane groups, respectively [65]. It was not possible to determine the contact angle for TPS-based blends due to the strong starch-water interaction, leading to fast adsorption and absorption of water in the polymeric surface.

\subsection{Spectral Characterization of the Films}

UV-Vis spectral properties of the PLA-based films were measured before and after a conditioning treatment realized in a climatic chamber at $25{ }^{\circ} \mathrm{C}$ and $50 \%$ of relative humidity (RH). As a preliminary example, Figure 6 shows the spectral measurements relative to PLA80 film. In particular, in Figure 6a, the total transmittances (solid lines) and the total reflectances (dash-dotted lines) measured before (black lines) and after (red lines) the treatment are shown. The spectra highlighted that, after the treatment, the transmittance of the film investigated decreased in mean of about $10 \%$ in the visible region (400-700 nm), while reflectance increased by about the same quantity. Total transmittance can be considered as the sum of the normal component transmitted at $90^{\circ}$ with respect to the film surface (Tn) and a complementary diffused component transmitted in the angular range $0^{\circ}<\alpha<90^{\circ}$ and $90^{\circ}<\alpha<180^{\circ}$. In Figure $6 \mathrm{~b}$, the normal transmittance $(T n)$ measured before (black line) and after (red line) the treatment of the PLA80 film was reported. As in the previous case, the transmittance decreases in all spectral regions after the treatment. Considering the light energy calculated by integrating the spectra in the visible region ( $400-700 \mathrm{~nm}$ ), a reduction of about $37 \%$ can be estimated. We repeated the same measurements on neat PLA film (spectra not reported), but no measurable variations in its spectral properties were observed. These results suggest that the presence of TPS in the film matrix favored the accumulation of water during the conditioning treatment. The presence of water resulted in the formation of droplets within the film, which increased its scattering properties, thus making it opaquer. The inset in Figure $6 \mathrm{~b}$ shows images of PLA80 film before and after the above treatment. These preliminary and worthy achievements open up the possibility of using this type of films to realize low-cost humidity sensors with good performance for promising applications in smart packaging technology. According to the previous finding, work is in progress to go in depth with other investigations, in order to widen the knowledge and encourage the feasibility of the film exploitation in bioplastic industrial applications. The results will be the subject of a forthcoming paper. 


\section{PLA80}

a

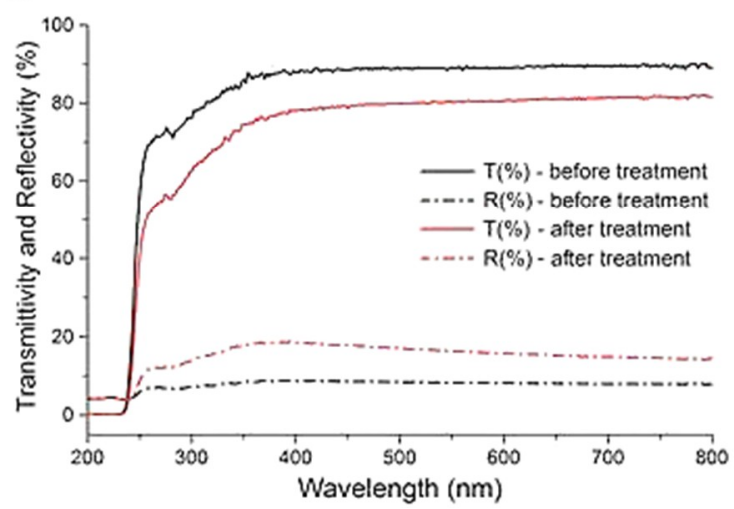

b

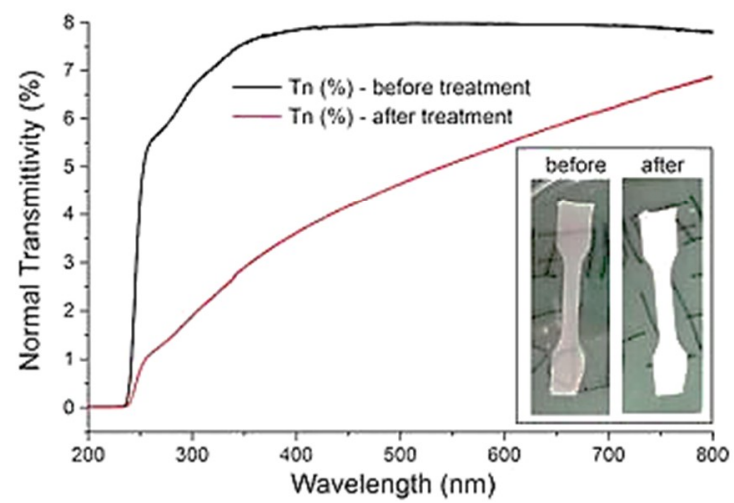

Figure 6. Spectral characterization of the PLA80 film: (a) total transmittances (solid lines) and the total reflectances (dash-dotted lines) measured before (black lines) and after (red lines) the treatment. (b) Normal transmittance measured before (black line) and after (red line) the treatment. In the inset, images of the PLA80 film before and after the treatment are shown.

\section{Conclusions}

The production of biodegradable food packaging materials has been widely increasing during the last decades, with research mainly focusing on improving the physicochemical and mechanical properties of the different bioplastics. In this work, biodegradable blends based on natural feedstock/raw materials, such as poly (lactic acid) (PLA) and corn thermoplastic starch (TPS), were prepared. An exhaustive study of the effects provided by the use of epoxidized oil coming from the non-edible Cardoon plant on the polymeric blend properties was carried out, in order to exploit the films' potential use for food packaging applications. The key results are detailed here. Firstly, FTIR-ATR analysis pointed out that only physical interactions occurred between ECO and the polymers; in particular, PLA was mainly involved in hydrogen bonding with the epoxidized oil, due to their similar hydrophobic behavior. The whole weight rescue of ECO from PLA-based films confirmed that the oil did not exude from the films; moreover, it was recovered in PLA fraction, thus suggesting a strong physical interaction occurring between this polymer and the plasticizer. This outcome accounted for the better performance of PLA80_ECO film compared to the TPS80_ECO one, in which the oil content was very low. Suffice it to say that, at molecular level, TGA and DSC analysis evidenced a slight improvement of PLA-TPS miscibility only in PLA-based films. In addition, morphological analysis confirmed the plasticizing action of ECO on the PLA matrix, highlighting a lean improvement of the interfacial adhesion between hydrophobic PLA and hydrophilic TPS, in PLA-based films. Further, the epoxidized oil strongly improved the barrier properties (WVP and $\mathrm{O}_{2} \mathrm{P}$ ) of all the films, likely developing a physical barrier to water and oxygen diffusion and solubilization.

Nevertheless, the epoxidized oil could not improve the mechanical response of the polymeric blends, due to both the outstanding polymer phase separation and shortage of physical entanglements between the polymers, and weak interfacial adhesion; all these drawbacks hindered suitable stress transfer through the interface. As a result, a negative deviation from the rule of mixture was found, and poor strength and a small deformation occurred. Although PLA-TPS-based films could represent eco-sustainable and cost-effective bioplastics to be exploited as smart food packaging materials, a huge effort should be made in order to improve polymer miscibility. The use of epoxidized oil as a compatibilizer could represent a valid strategy in order to preserve both the whole biodegradability of the system and the cost efficiency approach. To this aim, the work is in progress, as well as the investigations of the worthy spectral optical analyses. 
Author Contributions: In this paper, R.T. (Rosa Turco), R.O.-T., R.T. (Riccardo Tesser), S.M., S.C.-B., A.C.B., M.M., M.R., M.D.S. and G.S. equally and synergically assisted in the main steps of the research, leading to the final version of the manuscript. They participated to the coordinating and planning joint research activities, from the conceptualization and theoretical investigation, to the experimental analysis and data curation and validation. Particular contribution to the writing of the original draft, review and editing, supervision and project management was provided by G.S., R.T. (Rosa Turco) and S.M.

Funding: This research was funded by the grant PRIN: Progetti di Ricerca di Interesse Nazionale-Bando 2017-“Cardoon valorisation by integrated biorefinery (CARDIGAN)" of italian Ministero dell'Istruzione dell'Università e della Ricerca for the financial support (COD. 2017KBTK93).

Acknowledgments: The authors are grateful to Solvay Italy for having provided hydrogen peroxide and Massimo Fagnano for the cardoon seed oil. The authors also thank Maria Cristina Del Barone for the valid support in technical assistance of morphological analysis, performed at Laboratory of Scanning and Transmission electron Microscopy (LAMeST), “Augusto Sirigu” of Institute for Polymers, Composites and Biomaterials.

Conflicts of Interest: The authors declare no conflict of interest. The funders had no role in the design of the study, in the analyses or interpretation of data, in the writing of the manuscript and in the decision to publish the results.

\section{References}

1. Europe, P. Plastics-The Facts 2016. An Analysis of European Plastics Production, Demand and Waste Data. 2016. Available online: https://www.plasticseurope.org/application/files/4315/1310/4805/plastic-the-fact-2016. pdf (accessed on 3 June 2019).

2. Gregory, M.R. Environmental implications of plastic debris in marine settings-entanglement, ingestion, smothering, hangers-on, hitch-hiking and alien invasions. Philos. Trans. R. Soc. B Biol. Sci. 2009, 364, 2013-2025. [CrossRef] [PubMed]

3. Ren, X. Biodegradable plastics: A solution or a challenge? J. Clean. Prod. 2003, 11, 27-40. [CrossRef]

4. Mormile, P.; Petti, L.; Rippa, M.; Immirzi, B.; Malinconico, M. Monitoring of the degradation dynamics of agricultural films by IR thermography. Polym. Degrad. Stab. 2006, 92, 777-784. [CrossRef]

5. Luckachan, G.E.; Pillai, C.K.S. Biodegradable polymers-A review on recent trends and emerging perspectives. J. Polym. Environ. 2011, 19, 637-676. [CrossRef]

6. Shen, K.; Haufe, J.; Patel, M.K. Product Overview and Market Projection of Emerging Bio-Based Plastics; Final Report; Utrecht University: Utrecht, The Netherlands, 2009.

7. Nair, L.S.; Laurencin, C.T. Biodegradable polymers as biomaterials. Prog. Polym. Sci. 2007, 32, $762-798$. [CrossRef]

8. Erdogan Orhan, I.; Sener, B.; Choudhary, M.I.; Khalid, A. Acetylcholinesterase and butyrylcholinesterase inhibitory activity of some Turkish medicinal plants. J. Ethnopharmacol. 2004, 91, 57-60. [CrossRef] [PubMed]

9. Lopes, M.S.; Jardini, A.L.; Maciel Filho, R.J.P.E. Poly (Lactic Acid) production for tissue engineering applications. In Proceedings of the 20th International Congress of Chemical and Process Engineering CHISA, Prague, Czech Republic, 25-29 August 2012; pp. 1402-1413.

10. Farah, S.; Anderson, D.G.; Langer, R. Physical and mechanical properties of PLA, and their functions in widespread applications, A comprehensive review. Adv. Drug Deliv. Rev. 2016, 107, 367-392. [CrossRef]

11. Arrieta, M.; Dominici, F.; López, J.; Kenny, J. Bionanocomposite films based on plasticized PLA-PHB/cellulose nanocrystal blends. Carbohydr. Polym. 2015, 121, 265-275. [CrossRef]

12. Lim, M.H.; Chin, J.E.; Ko, H.M.; Kim, I.C.; Lee, H.B.; Im, S.Y.; Bai, S. Simultaneous degradation of phytic acid and starch by an industrial strain of Saccharomyces cerevisiae producing phytase and alpha-amylase. Biotechnol. Lett. 2008, 30, 2125-2130. [CrossRef]

13. Rasal, R.; Janorkar, A.; Hirt, D. Poly (lactic acid) modifications. Prog. Polym. Sci. 2010, 35, 338-356. [CrossRef]

14. Zhang, Y.; Rempel, C.; Liu, Q. Thermoplastic starch processing and characteristics-A review. Crit. Rev. Food Sci. Nutr. 2014, 54, 1353-1370. [CrossRef] [PubMed]

15. Pushpadass, H.A.; Marx, D.B.; Hanna, M.A. Effects of extrusion temperature and plasticizers on the physical and functional properties of starch films. Starch Stärke 2008, 60, 527-538. [CrossRef]

16. Ortega-Toro, R.; Santagata, G.; d'Ayala, G.; Cerruti, P.; Talens Oliag, P.; Amparo Chiralt Boix, M.; Malinconico, M. Enhancement of interfacial adhesion between starch and grafted poly ( $\varepsilon$-caprolactone). Carbohydr. Polym. 2016, 147, 16-27. [CrossRef] [PubMed]

17. Collazo-Bigliardi, S.; Cuello, R.E.; Ortega-Toro, R. Epoxidised soybean oil addition into starch- and PLA-based biocomposites. Contemp. Eng. Sci. 2018, 11, 1953-1960. [CrossRef] 
18. Liminana, P.; Garcia-Sanoguera, D.; Quiles-Carrillo, L.; Balart, R.; Montanes, N. Optimization of maleinized linseed oil loading as a biobased compatibilizer in poly (butylene succinate) composites with almond shell flour. Materials 2019, 12, 685. [CrossRef] [PubMed]

19. Sun, S.; Liu, P.; Ji, N.; Hou, H.; Dong, H. Effects of various cross-linking agents on the physicochemical properties of starch/PHA composite films produced by extrusion blowing. Food Hydrocoll. 2017, 77, 964-975. [CrossRef]

20. Ortega-Toro, R.; Collazo-Bigliardi, S.; Talens, P.; Chiralt, A. Thermoplastic starch: Improving their barrier properties. Agron. Colomb. 2016, 34, S73. [CrossRef]

21. Ortega-Toro, R.; Bonilla, J.; Talens, P.; Chiralt, A. Future of starch-based materials in food packaging. In Starch-Based Materials in Food Packaging; Academic Press: Cambridge, UK, 2017; pp. 257-305. [CrossRef]

22. Xiong, Z.; Li, C.; Ma, S.; Feng, J.; Yang, Y.; Zhang, R.; Zhu, J. The properties of poly (lactic acid)/starch blends with a functionalized plant oil: Tung oil anhydride. Carbohydr. Polym. 2013, 95, 77-84. [CrossRef]

23. Phetwarotai, W.; Potiyaraj, P.; Aht-Ong, D. Characteristics of biodegradable polylactide/gelatinized starch films: Effects of starch, plasticizer, and compatibilizer. J. Appl. Polym. Sci. 2012, 126, e162-e172. [CrossRef]

24. Orozco, V.; Brostow, W.; Chonkaew, W.; Lopez, B. Preparation and characterization of poly (lactic acid)-g-maleic anhydride + starch blends. Macromol. Symp. 2009, 277, 69-80. [CrossRef]

25. Feng Zuo, Y.; Gu, J.; Qiao, Z.; Tan, H.; Cao, J.; Zhang, Y. Effects of dry method esterification of starch on the degradation characteristics of starch/polylactic acid composites. Int. J. Biol. Macromol. 2014, 72, 391-402. [CrossRef]

26. Przybytek, A.; Sienkiewicz, M.; Kucińska-Lipka, J.; Janik, H. Preparation and characterization of biodegradable and compostable PLA/TPS/ESO compositions. Ind. Crop. Prod. 2018, 122, 375-383. [CrossRef]

27. Rigoussen, A.; Raquez, J.-M.; Dubois, P.; Verge, P. A dual approach to compatibilize PLA/ABS immiscible blends with epoxidized cardanol derivatives. Eur. Polym. J. 2019, 114, 118-126. [CrossRef]

28. Carbonell, A.; Samper, M.; Garcia, D.; Sanchez-Nacher, L.; Balart, R. Plasticization effect of epoxidized cottonseed oil (ECSO) on poly (lactic acid). Ind. Crop. Prod. 2017, 104, 278-286. [CrossRef]

29. Belhassen, R.; Vilaseca, F.; Mutjé, P.; Boufi, S. Thermoplasticized starch modified by reactive blending with epoxidized soybean oil. Ind. Crop. Prod. 2014, 53, 261-267. [CrossRef]

30. Masuda, T.; Goldsmith, P. World soybean production: Area harvested yield, and long-term projections. Int. Food Agribus. Man. Rev. 2009, 12, 143-162.

31. Turco, R.; Pischetola, C.; Di Serio, M.; Vitiello, R.; Tesser, R.; Santacesaria, E. Selective epoxidation of soybean oil in the presence of H-Y zeolite. Ind. Eng. Chem. Res. 2017, 56, 7930-7936. [CrossRef]

32. Turco, R.; Tesser, R.; Cucciolito, M.E.; Fagnano, M.; Ottaiano, L.; Mallardo, S.; Malinconico, M.; Santagata, G.; Di Serio, M. Cynara cardunculus biomass recovery: An eco-sustainable, nonedible resource of vegetable oil for the production of poly (lactic acid) bioplasticizers. ACS Sustain. Chem. Eng. 2019, 7, 4069-4077. [CrossRef]

33. Gominho, J.; Curt, M.; Lourenço, A.; Fernández, J.; Pereira, H. Cynara cardunculus L. as a biomass and multi-purpose crop: A review of 30 years of research. Biomass Bioenergy 2018, 109, 257-275. [CrossRef]

34. Toscano, V.; Sollima, L.; Genovese, C.; Melilli, M.G.; Raccuia, S.A. Pilot plant system for biodiesel and pellet production from cardoon: Technical and economic feasibility. Acta Hortic. 2016, 2016, 429-442. [CrossRef]

35. Fernando, A.; Costa, J.; Barbosa, B.; Monti, A.; Rettenmaier, N. Environmental impact assessment of perennial crops cultivation on marginal soils in the Mediterranean Region. Biomass Bioenergy 2017. [CrossRef]

36. Turco, R.; Vitiello, R.; Tesser, R.; Vergara, A.; Andini, S.; Di Serio, M. Niobium based catalysts for methyl oleate epoxidation reaction. Top. Catal. 2017, 60, 1054-1061. [CrossRef]

37. ASTM-E96. American standard test methods for water vapour transmission of materials. Am. Soc. Test. Mater. 1993.

38. Kizil, R.; Irudayaraj, J.; Seetharaman, K. Characterization of irradiated starches by using FT-Raman and FTIR spectroscopy. J. Agric. Food Chem. 2002, 50, 3912-3918. [CrossRef] [PubMed]

39. Nibler, J.W. Infrared absorption spectroscopy. J. Chem. Educ. 1978, 55, A316. [CrossRef]

40. Molinaro, S.; Boaro, M.; Sensidoni, A.; Lagazio, C.; Morris, M.; Kerry, J. Effect of nanoclay-type and PLA optical purity on the characteristics of PLA-based nanocomposite films. J. Food Eng. 2013, 117, 113-123. [CrossRef] 
41. Santagata, G.; Valerio, F.; Cimmino, A.; Dal Poggetto, G.; Masi, M.; Di Biase, M.; Malinconico, M.; Lavermicocca, P.; Evidente, A. Chemico-Physical and antifungal properties of poly (butylene succinate)/cavoxin blend: Study of a novel bioactive polymeric based system. Eur. Polym. J. 2017, 94, 230-247. [CrossRef]

42. Tiğlı Aydın, R.S.; Hazer, B.; Acar, M.; Gümüşderelioğlu, M. Osteogenic activities of polymeric soybean oil-g-polystyrene membranes. Polym. Bull. 2013, 70, 2065-2082. [CrossRef]

43. Balart, J.F.; Fenollar, V.F.; Boronat, T.; Sánchez-Nacher, L. Processing and characterization of high environmental efficiency composites based on PLA and hazelnut shell flour (HSF) with biobased plasticizers derived from epoxidized linseed oil (ELO). Compos. Part B Eng. 2016, 86, 168-177. [CrossRef]

44. Shin, B.Y.; Jang, S.H.; Kim, B.S. Thermal, morphological, and mechanical properties of biobased and biodegradable blends of poly (lactic acid) and chemically modified thermoplastic starch. Polym. Eng. Sci. 2011, 51, 826-834. [CrossRef]

45. Ke, T.; Sun, S.X.; Seib, P. Blending of poly (lactic acid) and starches containing varying amylose content. J. Appl. Polym. Sci. 2003, 89, 3639-3646. [CrossRef]

46. Martin, O.; Avérous, L. Poly (lactic acid): Plasticization and properties of biodegradable multiphase systems. Polymer 2001, 42, 6209-6219. [CrossRef]

47. Akrami, M.; Ghasemi, I.; Azizi, H.; Karrabi, M.; Seyedabadi, M. A new approach in compatibilization of the poly(lacticacid)/thermoplastic starch (PLA/TPS) blends. Carbohydr. Polym. 2016, 144, 254-262. [CrossRef] [PubMed]

48. Huneault, M.; Li, H. Morphology and properties of compatibilized polylactide/thermoplastic starch blends. Polymer 2007, 48, 270-280. [CrossRef]

49. Ferri, J.; Garcia, D.; Sanchez-Nacher, L.; Gimeno, O.; Balart, R. The effect of maleinized linseed oil (MLO) on mechanical performance of poly (lactic acid)-thermoplastic starch (PLA-TPS) blends. Carbohydr. Polym. 2016, 147, 60-68. [CrossRef] [PubMed]

50. Ferri, J.M.; Samper, M.D.; García-Sanoguera, D.; Reig, M.J.; Fenollar, O.; Balart, R. Plasticizing effect of biobased epoxidized fatty acid esters on mechanical and thermal properties of poly (lactic acid). J. Mater. Sci. 2016, 51, 5356-5366. [CrossRef]

51. Ning, W.; Xingxiang, Z.; Na, H.; Jianming, F. Effects of water on the properties of thermoplastic starch poly(lactic acid) blend containing citric acid. J. Thermoplast. Compos. Mater. 2010, 23, 19-34. [CrossRef]

52. Russo, R.; Malinconico, M.; Santagata, G. Effect of cross-linking with calcium ion on the physical properties of alginate films. Biomacromolecules 2007, 8, 3193-3197. [CrossRef]

53. Bader, H.G.; Göritz, D. Investigations on high amylose corn starch films. Part 3: Stress strain behaviour. Starch Stärke 1994, 46, 435-439. [CrossRef]

54. De Graaf, R.A.; Karman, A.P.; Janssen, L.P.B.M. Material properties and glass transition temperatures of different thermoplastic starches after extrusion processing. Starch Stärke 2003, 55, 80-86. [CrossRef]

55. Santos, E.F.; Reiznautt, Q.B.; Samios, D.; Nachtigall, S.M.B. Sunflower-oil biodiesel oligoesters/polylactide blends: Plasticizing effect and ageing. Polym. Test. 2014, 39, 23-29. [CrossRef]

56. Li, H.; Huneault, M.A. Effect of nucleation and plasticization on the crystallization of poly (lactic acid). Polymer 2007, 48, 6855-6866. [CrossRef]

57. Wurzburg, O.B. Modified Starches: Properties and Uses; CRC Press: Boca Raton, FL, USA, 1986.

58. Wang, N.; Yu, J.; Chang, P.R.; Ma, X. Influence of citric acid on the properties of glycerol-plasticized dry starch (DTPS) and DTPS/poly (lactic acid) blends. Starch Stärke 2007, 59, 409-417. [CrossRef]

59. Nešić, A.; Onjia, A.; Davidović, S.; Dimitrijević, S.; Errico, M.E.; Santagata, G.; Malinconico, M. Design of pectin-sodium alginate based films for potential healthcare application: Study of chemico-physical interactions between the components of films and assessment of their antimicrobial activity. Carbohydr. Polym. 2017, 157, 981-990. [CrossRef] [PubMed]

60. Müller, C.M.O.; Pires, A.T.N.; Yamashita, F. Characterization of thermoplastic starch/poly (lactic acid) blends obtained by extrusion and thermopressing. J. Braz. Chem. Soc. 2012, 23, 426-434. [CrossRef]

61. Cerruti, P.; Laurienzo, P.; Malinconico, M.; Carfagna, C. Thermal oxidative stability and effect of water on gas transport and mechanical properties in PA6-EVOH films. J. Polym. Sci. Part B Polym. Phys. 2007, 45, 840-849. [CrossRef]

62. Hertlein, J.; Singh, R.; Weisser, H. Prediction of oxygen transport parameters of plastic packaging materials from transient state measurements. J. Food Eng. 1995, 24, 543-560. [CrossRef] 
63. Zhang, Z.; Lim, L.-T.; Tung, M.A. Limonene transport and mechanical properties of EVOH and nylon 6,6 films as influenced by RH. J. Appl. Polym. Sci. 2001, 79, 1949-1957. [CrossRef]

64. Carlo, B. Sviluppo di Blend Polimerici per il Miglioramento delle Proprieta' Barriera di Polimeri per il Packaging Alimentare; University of Padova: Padova, Italy, 2012.

65. Shieh, Y.-T.; Liu, G.-L. Temperature-modulated differential scanning calorimetry studies on the origin of double melting peaks in isothermally melt-crystallized poly (L-lactic acid). J. Polym. Sci. Part B Polym. Phys. 2007, 45, 466-474. [CrossRef]

(C) 2019 by the authors. Licensee MDPI, Basel, Switzerland. This article is an open access article distributed under the terms and conditions of the Creative Commons Attribution (CC BY) license (http://creativecommons.org/licenses/by/4.0/). 